Check for updates

Cite this: J. Anal. At. Spectrom., 2021, 36,892

Received 17th December 2020

Accepted 1st March 2021

DOI: 10.1039/d0ja00516a

rsc.li/jaas

\section{Sensitive determination of mercury by magnetic dispersive solid-phase extraction combined with flow-injection-cold vapour-graphite furnace atomic absorption spectrometry $\dagger$}

\author{
J. C. García-Mesa, P. Montoro-Leal, S. Maireles-Rivas, M. M. López Guerrero (D) * \\ and E. Vereda Alonso (iD *
}

\begin{abstract}
Mercury is a non-essential trace element that is toxic to humans due to the bioaccumulation effect. In this work, a ferrofluid based on $\mathrm{Fe}_{3} \mathrm{O}_{4}$ @graphene oxide nanospheres together with an ionic liquid was used to develop a magnetic dispersive solid-phase extraction (MDSPE) method for the extraction of the complex formed between the chelating agent methyl thiosalicylate (MTS) and mercury. This MDSPE methodology was combined with an automatic analysis by flow injection-cold vapour-graphite furnace atomic absorption spectrometry (FI-CV-GFAAS). The developed semiautomatic method was applied to the determination of ultra-trace amounts of $\mathrm{Hg}(॥)$ in biological and environmental samples. Several analytical parameters for MDSPE and FI-CV-GFAAS, such as $\mathrm{pH}$, MTS concentration, eluent composition, extraction time, etc., were optimized by uni and multivariate methodologies. Under the optimized conditions, the \%RSD, detection limit and determination limit were $2.9 \%, 0.25 \mathrm{ng} \mathrm{L}{ }^{-1}$ and $4.9 \mathrm{ng} \mathrm{L}^{-1}$, respectively. The achieved preconcentration factor with the MDSPE methodology was 250 . The accuracy of the proposed method was verified using a Standard Reference Material (Mussel Tissue SRM 2976) and by determining the analyte content in spiked seawater and tap water samples collected from Málaga and Cádiz (Spain). The determined values were in good agreement with the certified values and the recoveries for the spiked samples were close to $100 \%$ in all cases. The results showed that the proposed method is simple, rapid, environmentally friendly, highly sensitive and accurate for determination of mercury in biological and environmental samples.
\end{abstract}

\section{Introduction}

Mercury is one of the most toxic elements, and its presence in the environment arises from anthropogenic and natural sources such as geothermal activity, volcanic events, weathering of rocks, coal and oil combustion, waste incineration, agricultural activities, metal refining and manufacturing: ${ }^{1-3}$ Upon exposure to mercury above the permissible limits, the human nervous system, immune system, brain, kidneys, heart, stomach and lungs can be seriously damaged. ${ }^{4}$ The World Health Organization (WHO) has set a limit of $1.6 \mu \mathrm{g}$ per $\mathrm{kg}$ body weight per week for total $\mathrm{Hg}$ due to the high bioaccumulation factor. ${ }^{5}$ For this reason, determination of mercury is an important subject for analytical scientists and environmentalists. For example, the Spanish government has established a maximum $\mathrm{Hg}$ concentration of $0.07 \mu \mathrm{g} \mathrm{L}^{-1}$ for continental superficial waters (RD 817/

Department of Analytical Chemistry, Faculty of Sciences, University of Malaga, Campus of Teatinos, 29071 Málaga,Spain.E-mail: eivereda@uma.es; mmlopez@ uma.es

$\dagger$ Electronic supplementary information (ESI) available. See DOI: 10.1039/d0ja00516a
2015). ${ }^{6}$ Moreover, some environmental samples present complex and highly saline matrices (seawater), with other transitional metals and noble metals, ${ }^{7}$ which may seriously affect the results. Due to the trace or ultra-trace level concentrations of mercury in environmental samples, highly sensitive analytical techniques are required, which can be combined with preconcentration/separation treatments in order to improve the sensitivity of the detection technique and remove matrix interferences. Mercury determination is performed by using different methods, such as inductively coupled plasma mass spectrometry (ICP-MS), cold vapour atomic fluorescence spectrometry (CV-AFS) and cold vapour atomic absorption spectrometry (CV-AAS). ${ }^{8}$ Thus, the most common pre-treatment used for mercury determination is cold vapour generation $(\mathrm{CV})^{9}$ due to its simplicity, speed and possible automation of the detection system. ${ }^{\mathbf{1 0}}$ In addition to $\mathrm{CV}$, a huge number of green analytical procedures have been reported in the bibliography for the preconcentration treatments, for example, solid-phase extraction (SPE $)^{11-13}$ and liquid-liquid extraction (LLE). ${ }^{14,15}$

The SPE methods present excellent properties such as rapid phase separation, high selectivity, low cost, less use of organic 
solvents, simple extraction, high recovery, high preconcentration factor and automation of more detection techniques. ${ }^{\mathbf{1 6}-19}$ Magnetic SPE (MSPE) is a new type of SPE developed by Šafaříková and Šafarík for enriching pollutants with magnetic materials. ${ }^{20}$ In MSPE, a magnetic adsorbent is added to the solution containing the target analytes. After adsorption of the analytes, the adsorbent is separated from the solution using an external magnetic field. Thus, filtration and centrifugation processes are avoided. ${ }^{21-23}$

The exploration of new magnetic nanomaterials by combining magnetic inorganic materials and non-magnetic adsorbents is an active research area in MSPE. The best adsorbents are nanomaterials due to their main advantages such as high surface-to-volume ratio, easy derivation procedures and unique properties. Among non-magnetic adsorbents, graphene oxide (GO) is characterized by being cheap and easily scalable to a high-volume production. In addition, GO is well-suited for chemical modification and subsequent processing. ${ }^{24}$ This sorbent possesses a large surface area and a high density of oxygen-containing polar functional groups on the surface (epoxy, carboxylic acid, carbonyl and hydroxyl groups), as well as a rich delocalized $\pi-\pi$ electron systems that make it interact strongly with organic compounds with benzene rings. ${ }^{25} \mathrm{GO}$ can be modified with magnetic nanoparticles (MNPs) for use in MSPE, which can reduce the equilibrium time due to the fast mass transfer. Different magnetic nanomaterials based on graphene have been used successfully as adsorbents for preconcentration and determination of mercury, such as $\mathrm{Fe}_{3} \mathrm{O}_{4} /$ $\mathrm{GO}^{26}$ and graphene $/ \mathrm{ZnFe}_{2} \mathrm{O}_{4} \cdot{ }^{27}$ On the other hand, nowadays, the preconcentration steps tend towards miniaturization, so solid-phase microextraction (SPME) ${ }^{28}$ dispersive liquid-liquid microextraction (DLLME), ${ }^{29}$ single-drop microextraction, ${ }^{30}$ and so on are being widely used as extraction techniques. ${ }^{7}$

Magnetic dispersive solid-phase extraction (MDSPE) was applied for the first time in 2013 by Farahani et al. ${ }^{31}$ In this technique, an adequate volume of a ferrofluid is quickly injected into an aqueous sample using a syringe. The large contact surface between the two phases accelerates the mass transfer processes and improves the extraction kinetics; in addition, the phase separation is facilitated with the aid of an external magnetic field. Ferrofluids are stable colloidal suspensions of magnetic nanomaterials in an ionic liquid, showing both magnetic and fluid properties. Ionic liquids (ILs) are solvents with unique physicochemical properties including negligible vapour pressure and ability to be miscible in water and organic solvents, and have attracted a lot of attention for use as extractants in microextraction techniques. ILs can bind to the carbon network structures of GO via $\pi-\pi$ electronic interactions causing strong connections by physical crosslinking. ${ }^{32}$ Metal ions tend to stay in the aqueous phase, but their hydrophobicity will be increased upon complexation with a suitable ligand. The complex formed can be quickly extracted in the ferrofluid.

To apply ferrofluids to the extraction/preconcentration of mercury and increase the efficiency towards mercury extraction during the preconcentration treatment, thiolate ligands can be used as mercury chelating agents. Thiosalicylic acid is an interesting heterodifunctional ligand. Combination of both hard (O) and soft (S) donor atoms and the ability of both carboxylate and thiolate groups to bridge two metal centres ${ }^{33,34}$ provide a multitude of bonding opportunities to metals in either their mono- or doubly deprotonated states. ${ }^{35,36}$ It is well known that thiosalicylic acid and its derivatives are organic ligands commonly used for medical purpose to treat mercury poisoning. ${ }^{37}$ The formed organic mercury complex can be easily extracted from the matrix during the MDSPE process. In this work, a magnetic sorbent material was fabricated by coupling magnetic iron nanoparticles (MNPs) and graphene oxide (GO), resulting in shell structured $\mathrm{Fe}_{3} \mathrm{O}_{4}$ @graphene oxide nanospheres called magnetic graphene oxide (MGO). The material was suspended in the ionic liquid (IL) 1- $n$-butyl-3methylimidazolium tetrafluoroborate $[\mathrm{BMIM}]\left[\mathrm{BF}_{4}\right]$, resulting in a ferrofluid with excellent adsorbent properties. Thus, a MDSPE/CV-GFAAS method was optimized for the determination of ultra-trace amounts of $\mathrm{Hg}$ in environmental water and biological samples, using the ferrofluid described and the chelating agent methyl thiosalicylate (MTS). The preconcentration efficiency of the developed method, due to MDSPE and CV, resulted in excellent detection and determination limits compared with other similar methods reported in the bibliography.

\section{Experimental}

\subsection{Equipment}

A Perkin Elmer Zeeman AAnalyst 600 atomic absorption spectrometer (Norwalk, CT, USA) with a longitudinal Zeeman effect background correction system was used for the determination of $\mathrm{Hg}$. A Perkin Elmer electrodeless discharge lamp (EDL) was used as the radiation source. The mercury absorbance was measured at $253.7 \mathrm{~nm}$ with a $0.7 \mathrm{~nm}$ spectral band pass. The employed atomizer was a transversely heated graphite tube with an integrated pyrolytic graphite platform. A Perkin Elmer FIAS400 AS System, which consists of two peristaltic pumps with PVC tubing of various diameters, a five-port way rotary and a gas-liquid separator with a PTFE membrane of $0.5 \mathrm{~mm}$ pore diameter for hydride generation, was used as the flow injection (FI) accessory controlled by the instrument software. The FIAS400 AS System was connected directly from the gas-liquid separator to the AAnalyst 600 using $26 \mathrm{~cm}$ long PTFE tubing (1.75 $\mathrm{mm}$ i.d.). The FI system and the GFAAS instrument were coupled and operated completely synchronously. Measurements were carried out in peak area mode (read time of $5 \mathrm{~s}$ ). The graphite furnace temperature program is shown in the ESI, Table S1. $\uparrow$ The graphite tubes were covered with Ir as a permanent modifier following the treatment described elsewhere. ${ }^{38}$

A pH meter and a conductivity meter Hatch (Loveland, CA, USA) were employed for $\mathrm{pH}$ and ionic strength adjustments, respectively.

An ultrasonic bath VWR (West Chester, PA, USA) Unique, model USC 2800, $40 \mathrm{kHz}$, and a Vortex VWR (West Chester, PA, USA), model UV-2500, multi tube vortex mixer were also employed.

For the evaluation of the accuracy of the proposed method, a reference material was digested in a Milestone ultraWAVE 
microwave oven (Sorisole, Italy) equipped with $25 \mathrm{~mL}$ PTFE/ TFM vessels.

\subsection{Reagents and solutions}

High purity reagents were used in all experiments. All glassware was cleaned with hot concentrated nitric acid and stored soaked in $10 \%$ (wt/wt) nitric acid, and was rinsed several times with water immediately before use. Doubly de-ionized water (18 $\mathrm{M} \Omega \mathrm{cm}$ ) obtained from a Millipore Milli-Q water system (Bedford, MA, USA) was used throughout.

$\mathrm{Hg}$ stock standard solution, $1000 \mathrm{mg} \mathrm{\textrm {L } ^ { - 1 }}$, from Merck (Darmstadt, Germany) was used. Standards of working strength were made immediately prior to use by appropriate dilution as required. In order to adjust the $\mathrm{pH}$ of standards and samples, a $1 \mathrm{M}$ solution of hydrochloric acid was prepared from hydrochloric acid, 37\% wt/wt, Merck (Darmstadt, Germany), art. number 113386. Finally, a $0.2 \%(w t / v)$ sodium tetrahydroborate(III), Acros Organics (Geel, Belgium), solution prepared in $0.1 \%$ (wt/v) $\mathrm{NaOH}$, Sigma Aldrich Chemie (Steinheim, Germany), was used as a reductant for the generation of $\mathrm{Hg}$ cold vapour.

For the synthesis of MGO, ferric chloride hexahydrate $\left(\mathrm{FeCl}_{3} \cdot 6 \mathrm{H}_{2} \mathrm{O}\right)$, ferrous chloride tetrahydrate $\left(\mathrm{FeCl}_{2} \cdot 4 \mathrm{H}_{2} \mathrm{O}\right)$, ammonium hydroxide $30 \%$ (wt/wt), methanol, sodium chloride and $\mathrm{H}_{2} \mathrm{SO}_{4} 98 \%$ were purchased from Merck (Darmstadt, Germany) and $\mathrm{H}_{2} \mathrm{O}_{2} 35 \%$ from Scharlab (Barcelona, Spain). 3Aminopropyltriethoxysilane was obtained from Fluka (Buchs, Switzerland). Brij 76C18EO10, tetraethoxysilane (TEOS), $N, N^{\prime}-$ dicyclohexylcarbodiimide (DCC), graphite, $\mathrm{NaNO}_{3}$ and $\mathrm{KMnO}_{4}$ were acquired from Aldrich Chemie (Steinheim, Germany). Ethanol was supplied by Carlo Erba (Milano, Italy).

For the Hg-complex (Hg-MTS), methyl thiosalicylate from Sigma Aldrich Chemie (Steinheim, Germany) was employed. The ionic liquid 1- $n$-butyl-3-methylimidazolium tetrafluoroborate ([BMIM] $\left[\mathrm{BF}_{4}\right]$ ) was purchased from Merck (Darmstadt, Germany).

The Standard Reference Material (SRM 2976) analysed to determine the accuracy of the proposed procedure was from the National Institute for Standard \& Technology (NIST): SRM 2976 Mussel Tissue. Seawater and tap water samples were collected in glass bottles (previously cleaned by soaking for $24 \mathrm{~h}$ in $10 \%$ (wt/wt) nitric acid and finally rinsed thoroughly with ultrapure water before use). Samples were immediately filtered by using a membrane of $0.45 \mathrm{~mm}$ pore size cellulose nitrate filters from Millipore (Bedford, MA, USA). After that, the samples were stored at $4{ }^{\circ} \mathrm{C}$ as recommended by Method 3010B from the Environmental Protection Agency (USA), for less than 3 days until analysis. Nitric acid $65 \%$ (wt/wt) was supplied by Merck (Darmstadt, Germany), art. number 100452.

\subsection{Synthesis of MGO and preparation of the ferrofluid}

The synthesis and detailed characterization of MGO (Fig. S1, ESI $\dagger$ ) and the preparation of the ferrofluid are described elsewhere. ${ }^{39}$ A description of the synthesis and characterization of MGO is given in the ESI. $\dagger$

\subsection{Sample preparation}

The dissolution of the Standard Reference Material (SRM 2976) was carried out as follows: the sample was accurately weighted directly on a digest vessel (0.4-0.5 $\mathrm{g}$ of the previously dried sample according to the provider's instructions). Then $4.0 \mathrm{~mL}$ of concentrated nitric acid, $4.0 \mathrm{~mL}$ of $30 \%$ hydrogen peroxide, and $1.0 \mathrm{~mL}$ of concentrated hydrochloric acid were added to the vessel. This mixture was subjected to microwave digestion with a power of $1400 \mathrm{~W}$ for $20 \mathrm{~min}$, and a cooling time of $15 \mathrm{~min}$. Finally, the $\mathrm{pH}$ was adjusted by decreasing the acidity with $\mathrm{NaOH}$ and by adding $1 \mathrm{M} \mathrm{HCl}$ solution and the solution was made up to $500 \mathrm{~mL}$ with Milli-Q water in a volumetric flask.

For seawater and tap water samples, aliquots of $5 \mathrm{~mL}$ and $20 \mathrm{~mL}$ of sample, respectively, were placed in a $50 \mathrm{~mL}$ volumetric flask, then $5 \mathrm{~mL}$ of $1 \mathrm{M} \mathrm{HCl}(\mathrm{pH} 1), 5 \mathrm{~g}$ of $\mathrm{NaCl}$, and 350 $\mu \mathrm{L}$ of $1 \% \operatorname{MTS}(\mathrm{v} / \mathrm{v})$ were added, and de-ionized water was added up to the mark.

All samples were analysed immediately after preparation.

\subsection{Extraction procedure}

Accurate volumes of sample or standard solutions of $\mathrm{Hg}$ were poured into adequate volumetric flasks to have a final concentration in the eluent of $10 \mu \mathrm{g} \mathrm{L}^{-1} \mathrm{Hg}$ (II), then MTS $1 \% \mathrm{v} / \mathrm{v}$ in ethanol and $\mathrm{NaCl}$ up to a final concentration of $0.007 \%(\mathrm{v} / \mathrm{v})$ and $10 \%(\mathrm{wt} / \mathrm{v})$, respectively, were poured. Finally, the $\mathrm{pH}$ was adjusted to 1.0 with $1 \mathrm{M} \mathrm{HCl}$ and the volumetric flasks were filled up to the mark with deionized water. The content of the flasks was then poured into polyethylene tubes. Then, the MDSPE was performed by injecting rapidly $220 \mu \mathrm{L}$ of the ferrofluid into the sample solution with a $0.5 \mathrm{~mL}$ syringe (equipped with a suitable needle). The ferrofluid forms a homogeneous suspension within the sample, and the contact was kept for $1 \mathrm{~min}$ in an ultrasonic bath for the extraction of the $\mathrm{Hg}$-MTS complex. In the following step, a magnet was placed at the bottom of the tube for the sorbent magnetic decantation and the solution turned clear in $1 \mathrm{~min}$. The supernatant was decanted.

Mercury was eluted from the sorbent by adding $2 \mathrm{~mL}$ of eluent $\left(\mathrm{HNO}_{3} 0.5 \%\right.$ and thiourea $\left.0.5 \%\right)$ and stirring by vortexing for $1 \mathrm{~min}$. Finally, the sorbent was separated using a magnet and the supernatant was poured into a polyethylene tube for mercury determination by FI-CV-GFAAS.

To determine the extraction process efficiency, a $100 \mathrm{ng} \mathrm{\textrm {L } ^ { - 1 }}$ $\mathrm{Hg}$ solution was prepared and extracted under optimal conditions. The supernatant was filtered and analysed by ICP-MS, showing a $\mathrm{Hg}$ concentration below the LOD. Then, the extraction efficiency was considered close to $100 \%$.

The FI system configuration is shown in Fig. 1, and it was operated as follows: during the $11 \mathrm{~s}$ sample loading period, with

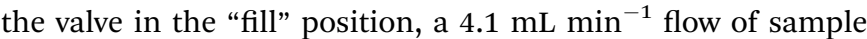
(standard or blank) at $\mathrm{pH} 1.0$ was pumped (via pump P1) through the $500 \mu \mathrm{L}$ loop located in the valve. Then, the valve position was changed to inject position and P1 was stopped, while $\mathrm{P} 2$ pumped water at a rate of $1.8 \mathrm{~mL} \mathrm{~min}^{-1}$ through the loop dragging the sample to the chemical vapour generator. Thus, the mercury merges with $0.6 \mathrm{~mL} \mathrm{~min}^{-1}$ flow of the 

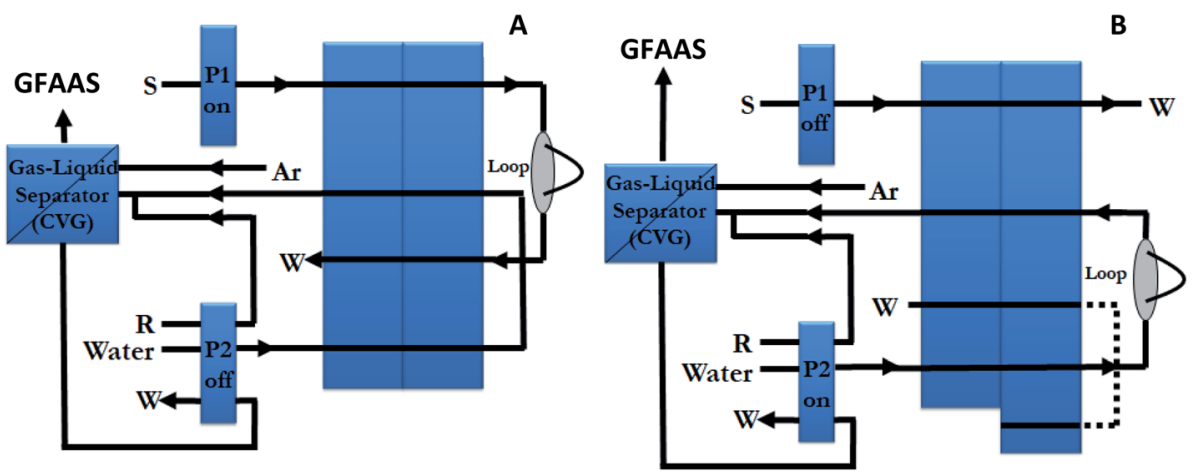

Fig. 1 Fl system schematic diagram for the loading step (A) and elution step (B). P1 and P2, peristaltic pumps; W, waste; S, sample; R, reductant.

reductant in the mixing coil, where direct generation of mercury vapour takes place. The gas generated and the solvent were then passed into the gas-liquid separator which separates gases from liquid. The liquid was drained, and the generated vapour was swept into the graphite furnace through the $26 \mathrm{~cm}$ tubing, until the tip of the autosampler arm, by a stream of $250 \mathrm{~mL} \mathrm{~min}{ }^{-1}$ argon. In this procedure, the FI system and the GFAAS instrument were coupled and operated completely synchronously.

\subsection{Optimization strategy}

The determination of ultra trace amounts of mercury in environmental water samples is difficult not only due to the low analyte concentrations present but also due to the complexity of the sample matrices. Following the chemical vapour generation, only the analyte vapours are conducted to the graphite tube, with the risk of interference being very small. The best signal of the analyte was used as optimization criteria. The chemical and FI system (Fig. 1) variables of the used manifold, which affect the pre-concentration and mercury vapour generation, were optimized using a final concentration of $10.0 \mu \mathrm{g} \mathrm{L}^{-1}$ $\mathrm{Hg}(\mathrm{II})$ in the eluent solution. The scanning of each standard, blank and sample was repeated three times.

Two different strategies were used: a one-at-a-time method (changing one parameter at a time while keeping the others constant) and a multivariate response surface experiment design.

Some parameters relevant to the optimization were elution of $\mathrm{Hg}$ in the manifold and reaction conditions for $\mathrm{CV}$ (reagent concentrations). For that reason, a response surface design was performed. The variables to be optimized were the concentrations of $\mathrm{NaBH}_{4}$, thiourea and $\mathrm{HNO}_{3}$. The lower and upper values given for each factor were $0.0 \%$ and $4.0 \%$ for $\mathrm{NaBH}_{4}$ concentration, $0.0 \%$ and $5.0 \%$ for thiourea concentration and $0.0 \%$ and $5.0 \%$ for $\mathrm{HNO}_{3}$ concentration. The response surface design used was a rotatable central composite design (CCD) which includes a $2^{3}$ factorial design ( 8 experiments), a $2 \times 3$ star design ( 6 experiments) and 3 centre points ( 3 experiments). The resulting 17 experiments required for that design were randomly performed, and as response function, the $\mathrm{Hg}$ signal (peak area) was chosen. The results of the experiments were processed using the statistical software Statgraphics Centurion
XVI. The significance of the effects was checked by analysis of the variance (ANOVA) and using $p$-value significance levels. This value represents the probability of the effect of a factor being due solely to random error. Thus, if the $p$-value is less than $5 \%$, the effect of the corresponding factor is significant.

Once the concentrations of the reductant and eluent solutions were optimized, the rest of the experimental parameters for the MDSPE/CV-GFAAS were optimized by the one-at-a-time method in order to obtain the best peak area signal.

\section{Results and discussion}

\subsection{Optimizing operating parameters}

The graphite furnace temperature programs were optimized by univariate way in experiments conducted with $10 \mu \mathrm{g} \mathrm{L} \mathrm{L}^{-1} \mathrm{Hg}$ (II), while running a blank in parallel. Ir was used as a permanent modifier. The optimized heating program for $\mathrm{Hg}$ can be seen in Table S1, ESI. $\dagger$

\subsection{Effect of $\mathbf{p H}$ on the collection of the analyte}

Since the solution $\mathrm{pH}$ affects the extent of complexation with MTS, which in turn determines the percentage of analyte retained by the MTS, the pre-concentration of $10 \mu \mathrm{g} \mathrm{L}^{-1} \mathrm{Hg}$ (II) ions from solutions buffered at different $\mathrm{pH}$ was studied. The $\mathrm{pH}$ was varied between 1.0 and 11.0. $\mathrm{pH} 1$ was obtained with $1 \mathrm{M}$

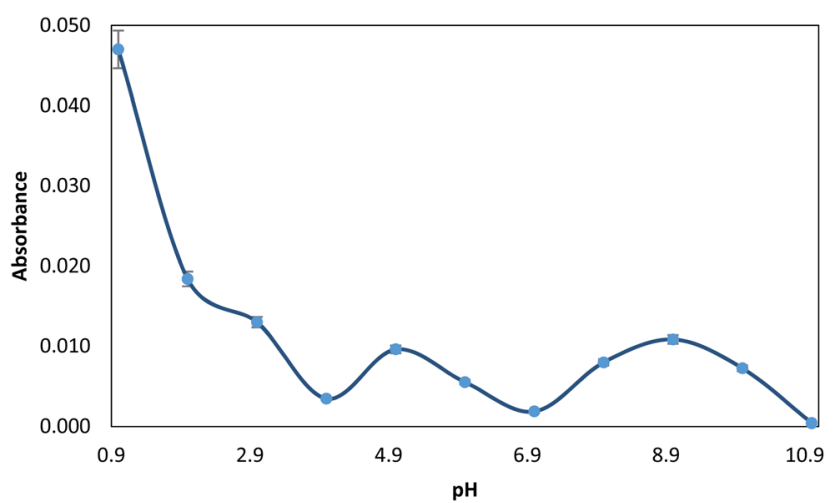

Fig. 2 Effect of $\mathrm{pH}$ on the extraction of $10 \mu \mathrm{g} \mathrm{L}{ }^{-1} \mathrm{Hg}(॥)$, prepared with $0.01 \%(\mathrm{v} / \mathrm{v}) \mathrm{MTS}, 0.5 \%(\mathrm{wt} / \mathrm{v}) \mathrm{NaCl}$, and the respective buffer $(\mathrm{pH} 1-11)$. 


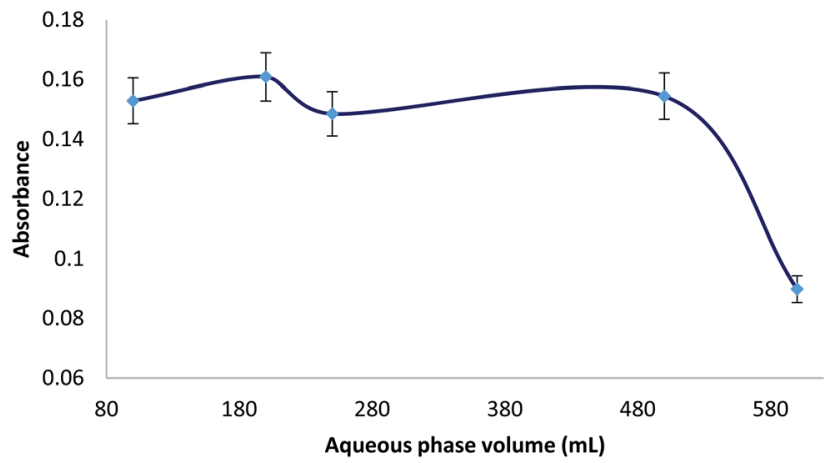

Fig. 3 Study of the aqueous phase volume for extraction of $10 \mu \mathrm{g} \mathrm{L}^{-1}$ $\mathrm{Hg}(॥)$, prepared with $0.007 \%(\mathrm{v} / \mathrm{v}) \mathrm{MTS}, 10 \%(\mathrm{wt} / \mathrm{v}) \mathrm{NaCl}$, and $1 \mathrm{M} \mathrm{HCl}$ until $\mathrm{pH}=1.0$.

$\mathrm{HCl}$, and the $\mathrm{pH}$ was adjusted from 2.0 to 5.0 by using glycine$\mathrm{HCl}$ or sodium acetate-acetic acid buffer, from 5.0 to 10.0 by using $\mathrm{NaOH}$-boric acid buffer and $\mathrm{pH}>10.0$ was obtained with $\mathrm{NaOH}$. As can be seen in Fig. 2, the maximum value of absorbance was observed at $\mathrm{pH}$ 1.0. This phenomenon can be explained considering the electronic interactions. ${ }^{39}$ At basic $\mathrm{pH}$, oxygen groups from the MGO surface are deprotonated, while the complex Hg-TMS is still neutral. Therefore, under basic conditions, the sorbent presents a negatively charged surface and the adsorption of an aromatic neutral complex is not favoured. Thus, acid pH maintains a non-charged surface which leads to more effective adsorption. So, in order to accomplish the determination of mercury, a pH value of 1 was chosen. For subsequent experiments, a solution of $1 \mathrm{M} \mathrm{HCl}$ was used to obtain this $\mathrm{pH}$.

\subsection{Optimization of the MDSPE/CV-GFAAS procedure}

As described above (Section 2.6), the concentrations of the eluent and reductant solutions were optimized through a CCD, and the rest of the experimental parameters for the MDSPE/CVGFAAS were optimized by the one-at-a-time method in order to obtain the best peak area signal.

The following parameters of the MDSPE were optimized: (a) concentration of MTS; (b) influence of ionic strength; (c) extraction time; (d) elution conditions and CV generation. Respective data and figures are given in the ESI. $\uparrow$ The following experimental conditions were found to give the best results: (a) a MTS concentration of $0.007 \%$ (Fig. S2, ESI $\dagger$ ), (b) a $\mathrm{NaCl}$ concentration of $10.0 \%$ (Fig. S3, ESI $\dagger$ ), (c) an extraction time between MGO and MTS-Hg complex of 1 min (Fig. S4, ESI $\dagger$ ) and (d) elution conditions and $\mathrm{CV}$ generation: $0.5 \%$ thiourea, $0.5 \%$ $\mathrm{HNO}_{3}$ and $0.5 \% \mathrm{NaBH}_{4}$ (Fig. S6, ESI $\dagger$ ), and a reductant flow rate of $0.6 \mathrm{~mL} \mathrm{~min}^{-1}$ (Fig. S7, ESI†).

\subsection{Study of sample volume}

Different aqueous phase (sample) volumes were studied from 100 to $600 \mathrm{~mL}$ (0.007\% MTS). All the experiments were carried out with $220 \mu \mathrm{L}$ of ferrofluid and $2 \mathrm{~mL}$ of eluent $\left(\mathrm{HNO}_{3} 0.5 \%\right.$, thiourea $0.5 \%$ ). Considering that the volume of eluent was 2 $\mathrm{mL}$, the ratio between sample and eluent volumes ranged from
50 to 300 . Therefore, the preconcentration factor was from 50 to 300. In Fig. 3, it can be seen that the extraction efficiency was found constant up to an aqueous sample volume of $500 \mathrm{~mL}$, and then a decrease was observed. This fact could be due to an incomplete elution of $\mathrm{Hg}$ from the ferrofluid at higher ratio of sample volume/eluent volume or an incomplete adsorption of $\mathrm{Hg}$ from a higher sample volume with the same adsorbent volume $(220 \mu \mathrm{L})$. Using the maximum aqueous phase volume $(500 \mathrm{~mL})$ and an eluent volume of $2 \mathrm{~mL}$, the preconcentration factor (PF) for the MDSPE method was 250. Moreover, considering the $\mathrm{CV}$ generation step, it can be said that the preconcentration factor of this method is over 250 .

\subsection{Figure of merit}

Under the optimal conditions described above, linear calibration graphs were obtained from 2 to $200 \mathrm{ng} \mathrm{\textrm {L } ^ { - 1 }}$ for $\mathrm{Hg}$ with reference to the original sample and $500 \mathrm{~mL}$ sampling volume. Thus, $\mathrm{Hg}$ was pre-concentrated 250 times. Correlation coefficients always better than 0.9903 were obtained. In order to determine the limits of detection and quantification (LOD and LOQ), a calibration graph in the range of $2-100 \mathrm{ng} \mathrm{\textrm {L } ^ { - 1 }}$ was built with six standards. The calibration equation was $y=0.00050 x$ $\left(\mu \mathrm{g} \mathrm{L}^{-1}\right)+0.0038$, with confidence intervals of \pm 0.00009 for the slope and \pm 0.0005 for the intercept. The LOD and LOQ, calculated as the concentration of the analyte giving signals equivalent to three and ten times, respectively, the standard deviation of the blank plus the net blank intensity, were $0.25 \mathrm{ng} \mathrm{L}^{-1}$ (LOD) and $4.9 \mathrm{ng} \mathrm{L}^{-1}$ (LOQ) for $\mathrm{Hg}$. The signal and standard deviation of the blanks (absorbance signals) used for these determinations were $0.00358 \pm 0.00008$.

The precision of the whole method was evaluated in terms of inter-day precision, using the relative standard deviation (RSD), calculated as the average of relative standard deviations of 2, 50 and $100 \mathrm{ng} \mathrm{L^{-1 }}$ standards measured on three days. The calculated inter-day precisions were $2.9,2.2$ and $1.4 \%$, respectively. The preconcentration factor calculated as the ratio of sample volume to eluent volume and considering that the extraction process efficiency was close to $100 \%$ (Section 2.5) was 250.

Table 1 Analytical applications, certified material

\begin{tabular}{llll}
\hline & & $\begin{array}{l}\text { Found } \pm \\
\text { standard error } \\
(\mu \mathrm{g}\end{array}$ & $\begin{array}{l}\text { Recovery } \\
(\%)\end{array}$ \\
Sample & Added $\left(\mu \mathrm{g} \mathrm{L}^{-1}\right)$ & $\left.\mathrm{L}^{-1}\right)$ & - \\
\hline Tap water & - & - & 100.0 \\
Spike 1 & 0.02 & $0.020 \pm 0.002$ & \\
Spike 2 & 0.06 & $0.056 \pm 0.003$ & 93.3 \\
Tarifa seawater & - & $0.018 \pm 0.006$ & - \\
Spike 1 & 0.04 & $0.053 \pm 0.006$ & 87.5 \\
Spike 2 & 0.12 & $0.140 \pm 0.007$ & 101.7 \\
Malaga seawater & - & $0.0075 \pm 0.0002$ & - \\
Spike 1 & 0.04 & $0.042 \pm 0.003$ & 86.3 \\
Spike 2 & 0.12 & $0.1297 \pm 0.0004$ & 101.8 \\
NIST 2976 Mussel & Certificate total value & \\
Tissue & $61.0 \pm 3.6 \mu \mathrm{kg}^{-1} 63 \pm 5\left(\mu \mathrm{g} \mathrm{kg} \mathrm{kg}^{-1}\right)$ & 103.3
\end{tabular}


Table 2 Comparison of the analytical performance data with the literature

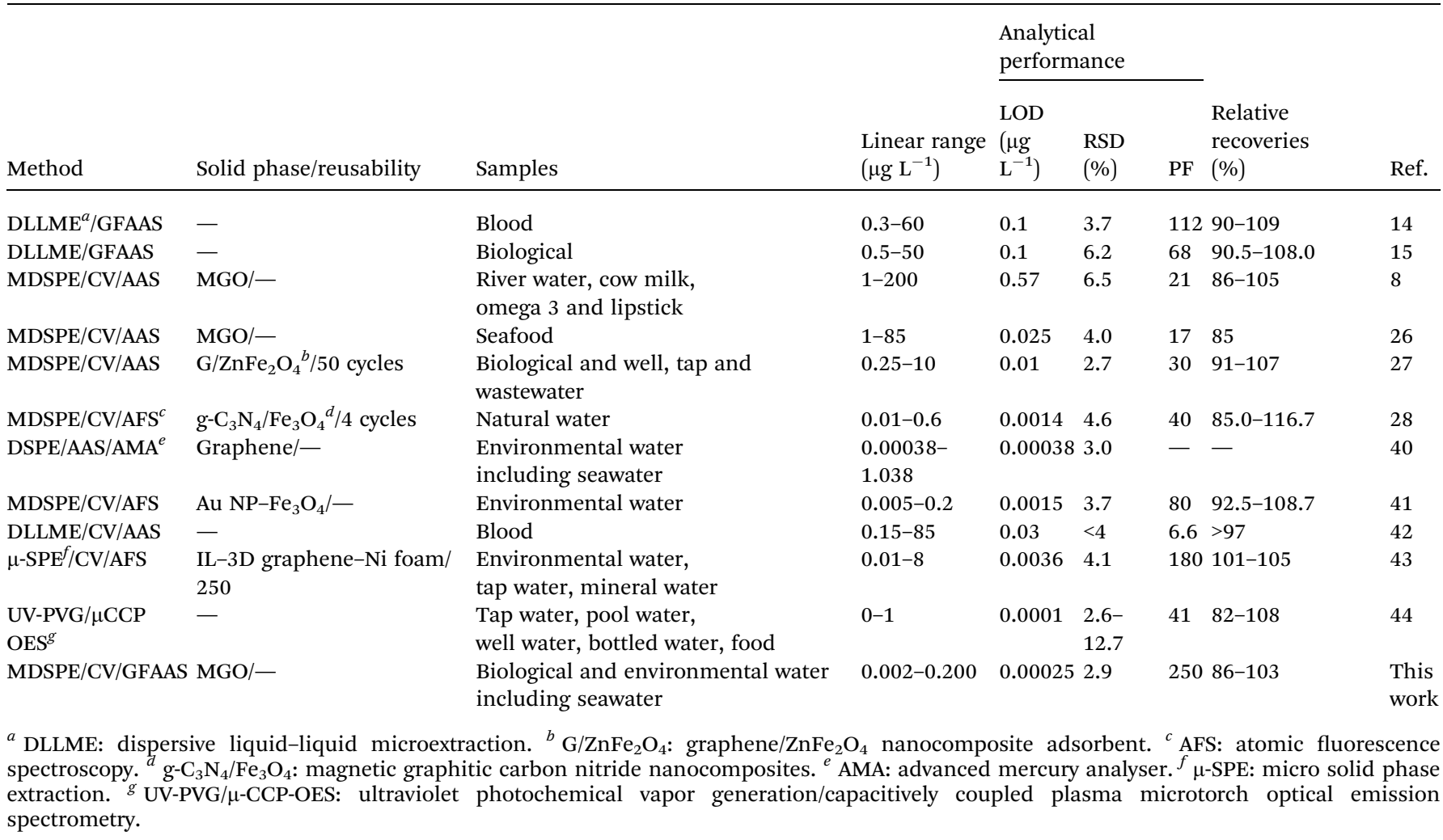

\subsection{Validation of the method}

The accuracy of the method was evaluated by using a Standard Reference Material (SRM 2976). Moreover, recovery experiments were carried out in real samples: tap water, Tarifa seawater and Malaga seawater. As shown in Table 1, the recoveries (\%) at different spiked concentrations were between 86.0 and $103.0 \%$, providing satisfactory results in terms of precision, even in real samples presenting complex matrices. No significant differences were observed for $p=0.05$ between the results and the certified value and the added concentrations according to the $t$ test for a confidence level of $95 \%\left(t_{\text {calculated }}=1.19\right.$ and $t_{\text {tabulated }}$ $=2.57$ ). All determinations were performed by external calibration with aqueous standards prepared by the same extraction procedure as for the samples. Although real samples have included trace elements such as transition metals, it can be said that there is no interference from these metals at $\mu \mathrm{g} \mathrm{mL}^{-1}$ concentrations. Therefore, the proposed procedure was validated and demonstrated to be accurate in $\mathrm{Hg}$ determination in a wide variety of sample matrices.

$\mathrm{Hg}$ (II) was found in seawater samples due to the high sensitivity of the method, and the concentrations $(0.018 \pm 0.006$ and $0.0075 \pm 0.0002 \mu \mathrm{g} \mathrm{\textrm {L } ^ { - 1 }}$ in Tarifa and Málaga seawater, respectively (Table 1)) were below the allowed limits by Spanish legislation (RD 817/2015) ${ }^{6}$ and within the normal concentration ranges.

For comparison purposes, the analytical performance data of similar methods reported in the literature are listed in Table 2.
A direct comparison of the figures of merit for the developed method with results from other workers is difficult due to the different experimental conditions. All the methods presented in Table 1 consist of preconcentration and determination procedures combined with AAS for the determination of $\mathrm{Hg}$ (II). As can be seen, the analytical performances, such as LOD, RSD, and PF, of the method reported in this work are the best. The preconcentration method on the ferrofluid was easy and the $\mathrm{Hg}$ preconcentration required only one minute and another minute for elution, being a very efficient procedure, with relative recoveries between 86 and 103\%. Besides the preconcentration on the ferrofluid, another preconcentration occurs on the graphite tube thanks to the Ir cover. To our knowledge, this is the first reported method that combines MDSPE and CV-GFAAS for $\mathrm{Hg}$ (II) determination. The use of $\mathrm{CV}$ generation and the preconcentration in the Ir permanent modifier explain the better results in the analytical performance of the method compared with recent literature methods.

\section{Conclusion}

In this work, a ferrofluid based on $\mathrm{Fe}_{3} \mathrm{O}_{4}$ @graphene oxide nanospheres together with an ionic liquid was used to develop a MDSPE method for the extraction of the complex formed between the chelating agent methyl thiosalicylate (a ligand used to treat mercury poisoning) and mercury. The procedure has resulted to be highly efficient in mercury extraction, being rapid (1 + 1 minute, pre concentration + elution); easy, the separation 
between the ferrofluid and the solution is achieved only with the use of a magnet and decantation; and green, since only small amounts of a non-toxic solvent are necessary. The combination of MDSPE with CV-GFAAS has resulted in high sensitivity towards mercury, and the analytical performances of the method reported in this work, such as LOD, RSD, and PF, compared very well to similar methods found in the bibliography. The method was validated by the analysis of a SRM of Mussel Tissue, and the analysis was performed with external calibration of $\mathrm{Hg}$ spiked environmental water samples including seawater. The relative recoveries were between 86 and $103 \%$, showing the selectivity of the method because these samples have complex and highly saline matrices including trace elements such as transition metals.

\section{Author contributions}

E. I. Vereda Alonso: conceptualization, methodology, formal analysis, writing - original draft, writing - review \& editing, software, data curation, supervision, resources, funding acquisition. M. M. López Guerrero: conceptualization, methodology, formal analysis, writing - original draft, writing review \& editing, data curation, supervision, resources. S. Maireles-Rivas: investigation, methodology. P. Montoro Leal: investigation, methodology, writing - review \& editing, software, formal analysis, data curation. J. C. García-Mesa: investigation, methodology, validation, software, formal analysis, writing review \& editing, data curation. All authors have read and agreed to the published version of the manuscript.

\section{Conflicts of interest}

The author(s) declare that they have no competing interests.

\section{Acknowledgements}

The authors thank the University of Malaga (Proyecto Puente UMA) and Junta de Andalucía, Project UMA18FEDERJA060 for supporting this study and the Spanish Ministerio de Ciencia y Tecnología for the fellowship FPU18/05371.

\section{References}

1 J. Wang, X. Feng, C. W. N. Anderson, Y. Xing and L. Shang, J. Hazard. Mater., 2012, 221-222, 1.

2 Z. Tang, F. Fan, S. Deng and D. Wang, Ecotoxicol. Environ. Saf., 2020, 202(110950), 1.

3 S. A. Silyutin, S. A. Epshtein and T. O. Gushchina, Mining Informational and Analytical Bulletin, 2020, 5, 5.

4 K. H. Kim, E. Kabir and S. A. Jahan, J. Hazard. Mater., 2016, 306, 376.

5 A. B. Shabestari, B. A. Adergani, M. Shekarchi and S. M. Mostafavi, Ekoloji, 2018, 27, 1935.

6 BOE núm. 217 de 11/09/2015. Real Decreto 817/2015 de 11 de septiembre, por el que se establecen los criterios de seguimiento y evaluación del estado de las aguas superficiales y las normas de calidad ambiental, 2015, pp. 80582-80677.
7 M. M. López Guerrero, E. Vereda Alonso, J. M. Cano Pavón, M. T. Siles Cordero and A. Garcia de Torres, J. Anal. At. Spectrom., 2016, 31, 975.

8 S. Jamshidi, M. K. Rofouei, S. Seidi and Å. Emmer, Sep. Sci. Technol., 2019, 55, 1505.

9 T. Zangmo and A. Siripinyanond, Anal. Chim. Acta, 2019, 1085, 29.

10 N. Ferrúa, S. Cerutti, J. A. Salonia, R. A. Olsina and L. D. Martinez, J. Hazard. Mater., 2007, 141, 693.

11 M. M. López Guerrero, M. T. Siles Cordero, E. Vereda Alonso, A. García de Torres and J. M. Cano Pavón, Microchem. J., 2017, 132, 274.

12 M. M. López Guerrero, M. T. Siles Cordero, E. Vereda Alonso, J. M. Cano Pavon and A. García de Torres, J. Anal. At. Spectrom., 2015, 30, 1169.

13 J. C. Garcia-Mesa, P. Montoro Leal, M. M. Lopez Guerrero and E. I. Vereda Alonso, Microchem. J., 2019, 150, 104141.

14 R. Akramipour, M. R. Golpayegani, S. Gheini and N. Fattahi, Talanta, 2018, 186, 17.

15 M. Pirsaheb and N. Fattahi, Anal. Methods, 2015, 7, 6266.

16 W. A. W. Ibrahim, L. I. A. Ali, A. Sulaiman, M. M. Sanagi and H. Y. Aboul-Enein, Crit. Rev. Anal. Chem., 2014, 44, 233.

17 L. Zhang, X. Chang, Z. Hu, L. Zhang, J. Shi and R. Gao, Microchim. Acta, 2010, 68, 79.

18 E. Yavuz, S. Tokalıoglu, H. Sahan and S. Patat, Food Chem., 2016, 194, 463.

19 Y. Zhai, S. Duan, Q. He, X. Yang and Q. Han, Microchim. Acta, 2010, 169, 353.

20 M. Šafaříková and I. Šafarík, J. Magn. Magn. Mater., 1999, 194, 108.

21 Q. Han, Z. Wang, J. Xia, S. Chen, X. Zhang and M. Ding, Talanta, 2012, 101, 388.

22 H. A. Zadeh and Z. Talleb, Talanta, 2015, 134, 387.

23 J. P. Wasylka, N. Szczepańska, M. de la Guardia and J. Namieśnik, TrAC, Trends Anal. Chem., 2016, 77, 23.

24 X. Gao, J. Jang and S. Nagese, J. Phys. Chem. C, 2009, 14, 832.

25 D. R. Dreyer, A. D. Todd and C. W. Bielawski, Chem. Soc. Rev., 2014, 43, 5288.

26 S. Seidi and M. Fotouhi, Anal. Methods, 2017, 9, 803.

27 E. Yavuz, Ș. Tokalıŏ̆lu and Ș. Patat, Microchem. J., 2018, 142, 85.

28 M. Shi, X. Yang and W. Zhang, Anal. Chim. Acta, 2019, 1074, 33.

29 A. N. Anthemidis and K. I. G. Ioannou, Talanta, 2009, 80, 413.

30 M. Mirzaei, M. Behzadi, N. Mahmoud Abadi and A. Beizaei, J. Hazard. Mater., 2011, 186, 1739.

31 M. D. Farahani, F. Shemirani and M. Gharehbaghi, Talanta, 2013, 109, 121.

32 J. Lee and T. Aida, Chem. Commun., 2011, 47, 6757.

33 M. Nayaka, A. K. Singhb, P. Prakashb, R. Kantc and S. Bhattacharyaa, Inorg. Chim. Acta, 2020, 501, 119263.

34 T. Wehr-Candler and W. Henderson, Coord. Chem. Rev., 2016, 313, 111.

35 C. Ma, Q. Zhang, R. Zhang and D. Wang, Chem.-Eur. J., 2006, 12,420 . 
36 J. G. Melnick, K. Yurkerwich, D. Buccella, W. Sattler and G. Parkin, Inorg. Chem., 2008, 47, 6421.

37 S. Asadi, B. Zhang, Z. Weng, A. Angelidou, D. Kempuraj, K. D. Alysandratos and T. C. Theoharides, Int. J. Immunopathol. Pharmacol., 2010, 23, 1015.

38 E. Vereda Alonso, M. M. López Guerrero, P. Colorado Cueto, J. Barreno Benítez, J. M. Cano Pavón and A. García de Torres, Talanta, 2016, 153, 228.

39 X. Jia, D. Gong, J. Wang, F. Huang, T. Duan and X. Zhang, Talanta, 2016, 160, 437.
40 B. Duval, A. Gredilla, S. Fdez-Ortiz de Vallejuelo, E. Tessier, D. Amouroux and A. de Diego, Microchem. J., 2020, 154, 104549.

41 W. Zhang, C. Sun and X. Yang, Anal. Methods, 2014, 6(9), 2876.

42 H. Shirkhanloo, A. Khaligh, H. Z. Mousavi, M. M. Eskandari and A. A. Miran-Beigi, Chem. Pap., 2015, 69(6), 779.

43 A. C. Sotolongo, M. M. Messina, F. J. Ibanez and R. G. Wuilloud, Talanta, 2020, 210, 120614.

44 E. Covaci, M. Senila, C. Tanaselia, S. B. Angyus, M. Ponta, E. Darvasi, M. Frentiu and T. Frentiu, J. Anal. At. Spectrom., 2018, 33(5), 799. 